\title{
Einar Tandberg-Hanssen
}

\section{Brigitte Schmieder ${ }^{1}$, Jean-Claude Pecker ${ }^{2}$, Allen Gary ${ }^{3}$, S.T. Wu ${ }^{3}$, Ronald Moore ${ }^{4}$ and Else Biesmann ${ }^{5}$}

${ }^{1}$ Observatoire de Paris, LESIA, Meudon, France, ${ }^{2}$ Académie Française, Paris, ${ }^{3}$ University of Alabama, Hunstville, AL, US, ${ }^{4}$ NASA/Marshall Space Flight Center, Hunstville, AL, US, ${ }^{5} 10160$ Canyon Place, Rapid City, SD 57702, US. email: brigitte.schmieder@obspm.fr

\section{Einar Tandberg-Hanssen and Solar Physics (Brigitte Schmieder's speech)}

Dear Colleagues,

I would like to report first on the scientific career of Einar Tandberg-Hanssen: how he became a Solar Physicist particularly interested in prominences. In the second part of my talk I will show what he brought to the French community from the science perspective.

Einar Tandberg Hanssen was born on the 6 August 1921 in Bergen in Norway.

After WWII he studied Astrophysics, Stellar, and Solar Physics. He worked with S. Rossland and E. Jensen in Oslo. He built the telescope of the Observatory in Blindern (University of Oslo). In 1951 he went to the Astrophysics Institute (IAP) in Paris and started his collaboration with the French scientists: Chalonge, Dollfus, Martres, Michard, Pecker, Schatzman, Steinberg ... From 1952-1959, with Zirin and Pecker in California, he worked on the abundance of Beryllium in stellar atmospheres and on the classification of prominences according to their spectra.

For a short time during this period he visited England and worked on radio astronomy. Finally he came back to Oslo as a professor and gave lectures on Solar Physics for two years between 1959-1961. In 1960 he presented his thesis on "An Investigation of the Temperature Conditions in Prominence".

He was interested in the role of the magnetism in the exchange between cool prominences and the hot corona. He followed the polarization measurements made by Ratier at Pic du Midi in 1975 and the theory of the Hanle effect (Sahal, Bommier, Leroy 1977), which allows the derivation of the angle between the vector magnetic field in prominences and the local vertical on the solar surface. The conclusion of the latter study was that in prominences the magnetic field lines are horizontal and not, as they looked, vertical. MHD models appeared to take account of this discovery (the models of Kuperus and Raadu, 1974 and Kieppenhan-Schluter, 1957)

I personally started to know Einar just after my thesis on the propagation of waves in the solar atmosphere, when the Solar Maximum Mission (SMM) was launched in 1980. Einar was the Principal Investigator of the spectrometer on board SMM called UVSP. He travelled between Hunstville (MSFC) and Washington (GSFC) and organized several workshops (Figure 1 top left panel). The French scientists: J.-C. Pecker, G. Simon, B. Schmieder, P. and N. Mein, proposed a program on the "Detection of the Moreton waves in UV (CIV line)" to be run on this instrument. The program was accepted by the UVSP team. This lead to the theses of J.-M. Malherbe, P. Démoulin on the "Dynamics of filaments" and 14 refereed publications of Tandberg-Hanssen co-signed with the Meudon group. He had many other collaborators in different institutes in France: S. Koutchmy, J.-C. Vial, Z. Mouradian, J-C. Hénoux, P. Lantos, and J.L. Leroy. 


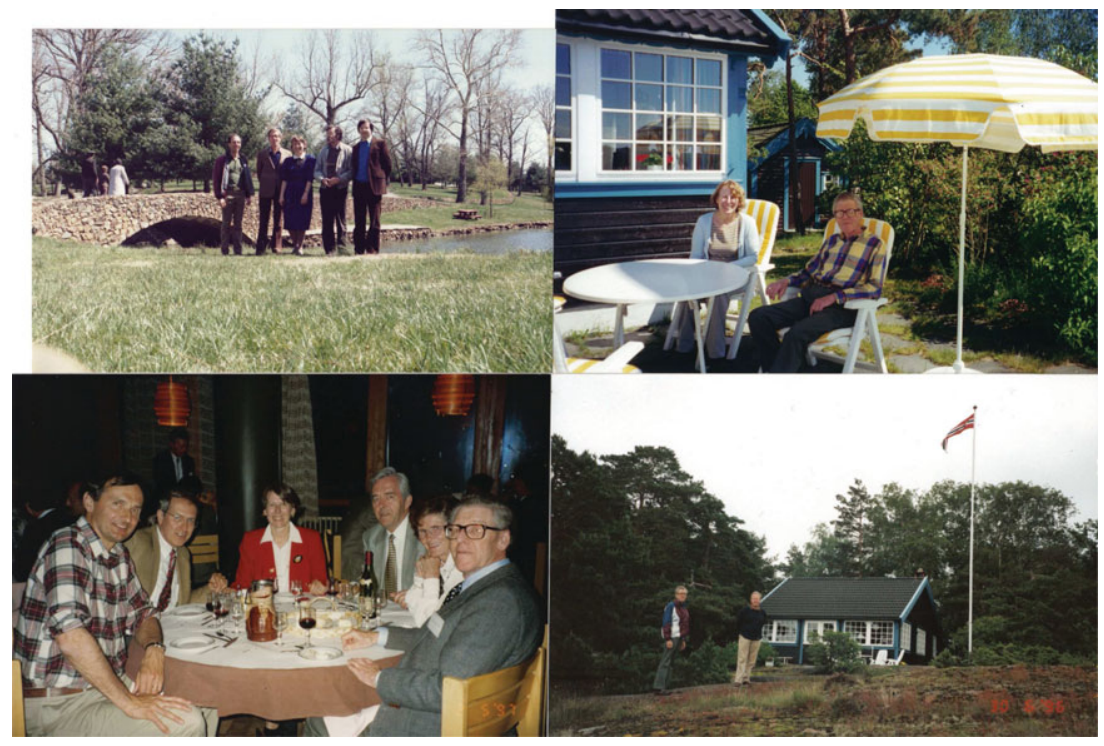

Figure 1. Einar Tandberg-Hanssen (top left) in Airlie (US) during a SMM workshop in 1989 (Art Poland, Einar, Brigitte Schmieder, Guy Simon, Jean Marie Malherbe); (bottom left) Einar Tandberg-Hanssen in Oslo with Pierre Foukal, David Rust, Brigitte Schmieder, Oddbjorn Engvold and his spouse, Einar: (right panels) Einar in front of his cabin in Sandefjord in 1996. (Figure adapted from Tandberg-Hanssen 2011)

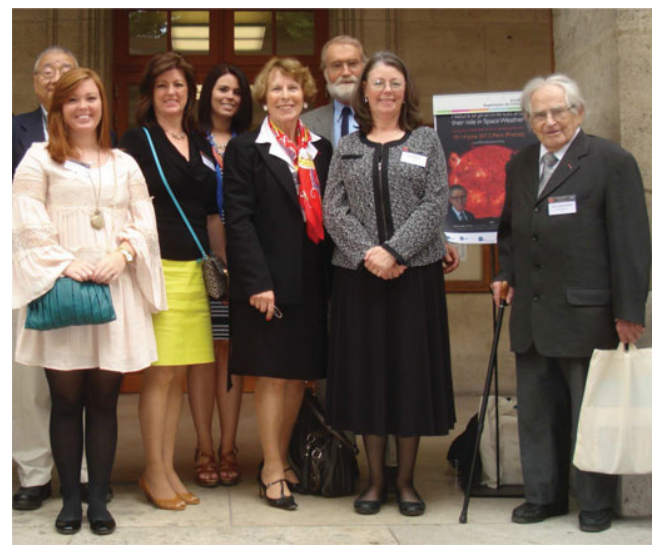

Figure 2. The daughters and grand-daughters of Einar in Paris on June 10, 2013 (from left to right: S.T.Wu, Jacquelyn, Karin, and Jennifer Brock, Brigitte Schmieder, Ronald Moore, Else Biesmann, Jean Claude Pecker).

Einar brought many things to our group in Meudon. We learned how to work in a team on a project and not to work alone. He was very convivial and also very well organized. He transmitted to us this capability. He opened our department of the Observatory of Paris to Space Research and showed how it is important to observe in different wavelengths. With him we acquired a great number of collaborations in the United States and in Norway. One Norwegian PhD student (Jun Elin Wiik) worked on her PhD in our laboratory and get a French thesis in 1994. I got a part-time fellowship of Professor in Oslo between 1996 and 2006, working with Oddbjorn Engvold and his students on fine structures in prominences (Figure 1 bottom left panel). For us, and particularly for me, Einar was a 
very good friend. He invited me to Sandefjord to visit his "Cabin" along the fjord (Figure 1 right panels).

I knew his wife Erna very well and remember her last sentences at the IAU General Assembly in La Hague in 1994, announcing to me her future death "I have achieved what I wanted to do in my life, it is fine for me to leave this world". I was also very surprised to receive an email transmitted by J.L. Leroy from Einar six months before his death. "I have been diagnosed with ALS, also called Lou Gehrig's disease, so we will not meet again. I would appreciate if you would let the Schmieders know this and all my old friends at Meudon. I am doing all right, but weak". He died on the 22 July 2011 in Huntsville.

We lost a great scientist and it is a great honor for me to be allowed to organize this IAU Symposium on prominences in memory of him. He loved Paris. He was in Paris every year "aux Ides" of March for the IAU FAG meetings. He would have like to attend this meeting. He attended the last one in Aussois in 1997 (IAU S167) . His daughters are here and for us it is a part of him.

References :

Tandberg-Hanssen 2011, Solar Physics, 269, 237

\section{Einar Tandberg-Hanssen in the 60's (Jean-Claude Pecker speech)}

Dear Colleagues;

I am amongst you the one who knew Einar and Erna Tandberg-Hanssen for the longest time, more than sixty years! Allow me to say a few words about the many occasions during which we met and became friends.

They were Norwegians. Actually, in the post-war years, remember, between-countries trips were quite difficult, even within Europe. But, due to the diligent action of Colonel F.J.M. Stratton, General Secretary of the IAU, and eager to organize the "exchange" of astronomers, some international exchanges were organized. And this created indeed excellent relations, in particular, between the French astronomers, the young ones especially, and their colleagues in Scandinavia, particularly in Norway. Following Vova Kourganoff, I spent some time at Oslo, in order to be acquainted with Svein Rosseland, then a key figure of the theory of stellar-solar atmospheres. During the same period, Einar and Erna spent two years in Paris, principally at the Institut d'Astrophysique, where the attractive figure of Daniel Chalonge acted as a magnet to young people.

Very soon, we felt a great sympathy for each other. The quiet and smiling behaviour of Einar, his competence, and seriousness, impressed me, as did the bright smile of the charming Erna, also a very competent scientist. I could not separate one from the other in my tribute to this talented and happy couple.

Later on, I had the pleasure to be at the HAO, in Boulder, at the time when Walter Roberts was its powerful and cheerful Director, and at the same time as the TandbergHanssens. He was by then becoming "the" expert in the physics of solar prominences. That field of research was the symbol of his life-track, observing and understanding better and better the physics of matter within the magnetic fields of the solar corona. I remember a long discussion about spiraling motions in prominences, about which I had published a paper with Don Billings, a good friend of both Einar and myself.

After that time, we met of course many times, at IAU meetings, or elsewhere. And we kept a very solid and quiet friendship. I always admired, along the years, Einar's serenity, his deep concern for scientific rigour, but also his very subtle sense of humour. We miss him. We miss them.

I am glad to have been able to say these few words of respect and friendship in front of their children. His daughter will now speak about her parents.

Thank you for your attention. Jean Claude Pecker (Figure 2). 


\section{Einar Tandberg-Hanssen in Hunstville (Allen Gary, S.T. Wu and Ronald Moore)}

In 1974, Dr. Einar Tandberg-Hanssen left the High Altitude Observatory at the National Center for Atmospheric Research in Boulder, Colorado to join the Space Sciences Laboratory at NASAs Marshall Space Flight Center (MSFC) in Huntsville, Alabama. There, he was a Senior NASA Research Scientist and later served as Deputy Director. He served as Director from 1987 until his retirement from NASA in 1993. He promptly took a part-time post at the Center for Space Plasma and Aeronomic Research at The University of Alabama in Huntsville where he worked until his death.

During his tenure at NASA, Einar along with Dr. Mona Hagyard and Dr. S. T. Wu, built up a substantial, internationally-based group of solar physicists at MSFC and UAH. He was lead investigator on two instruments aboard NASA spacecraft: the S-056 X-ray Event Analyzer on the "Skylab" Apollo Telescope Mount (which provided pioneering, high-time-cadence temperature and density information on solar X-ray-emitting regions) and the Ultraviolet Spectrometer and Polarimeter on the Solar Maximum Mission (which carried out sweeping new studies of EUV emission from solar active regions and flares). He received the NASA Exceptional Service Medal.

Dr. Tandberg-Hanssen's books about various aspects of solar activity, viz. Solar Activity (Blaisdell, 1967), Solar Prominences (Reidel, 1974), The Physics of Solar Flares (with A. G. Emslie) Cambridge, 1988, and The Nature of Solar Prominences (Reidel, 1995) have become international standard works within the discipline of solar physics.

Dr. Tandberg-Hanssen's Solar Physics Memoir paper entitled "Solar Prominences An Intriguing Phenomenon" was recently published before his death and can be downloaded via http:www.springerlink.com/content/1166j74k577kv332/. The article starts with an autobiographical account, where the author relates how his several study trips abroad gradually led him to the study of solar physics in general, and prominences in particular. Einar's residence as a research fellow at the Instut d'Astrophysique in Paris in the 1950s laid the foundation for a lifelong interest in France and French culture. His great interest and knowledge of French medieval churches, as well as the Norwegian state churches is reflected in two books "Letters to My Daughters" (Ivy House Pub. Group, 2004), and "The Joy of Travel: More Letters to My Daughters" (Pentland Press, 2007), which serve as a review, tourist guide and history book shaped in the form of letters home to his two daughters from his many travels in Norway and France.

This image (Figure 3) of Einar with a unicycle was captured at the end of a photographic session with Julia Gary. Einar had requested a portrait for his book, "The Joy of Travel: More Letters to My Daughters". After the formal session, Allen Gary brought out his unicycle, placed it next to Einar, whose quizzical look quickly changed into a whimsical grin as he posed in his usual aristocratic manner. This photographic event in 2006 was the culmination of a dinner which occurred in the early 1980s and was hosted by Einar and Erna in Huntsville, Alabama for Brigitte Schmieder, one of the editors of this symposium. At that time Einar was engaged as the principal investigator for NASA Solar Maximum Missions Ultraviolet Spectrometer/Polarimeter experiment working with Bruce Woodgate, Grant Athay, Jacques Beckers, and John Brandt, Dick Shine, Art Poland, and groups at Marshall Space Flight Center, Goddard Space Flight Center, University of Colorado, The University of Alabama in Huntsville, and the Observatoire de Paris. At this dinner, Julia Gary mentioned that she had just come from a local French group. The Tandberg-Hanssens were excited to learn about the Huntsville group and decided to join. The French group frequently met at the Gary's home and after Ernas death in 1994, the tradition of inviting Einar to remain for dinner was begun. The 


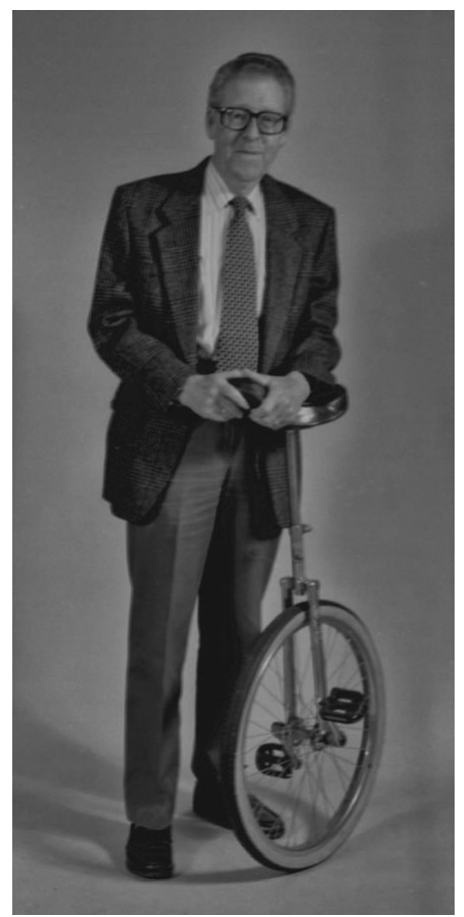

Figure 3. Einar Tandberg-Hanssen with a unicycle In Hunstville in 1997 (@Julia Gary)

dinner discussions included solar science, photography, the art and history of cathedrals, and the culture and literature of France, as always, accompanied by Einars insightful, aristocratic Norwegian intellect and twinkle, and, of course, une bouteille de vin rouge français. The enthusiastic discussions of Einar's letters to his daughters in the Huntsville French group and in the dinner conversations led to the publication of his two books and the photographic portrait session.

Einar was a true scholar and true gentleman. As evidence by his papers, his books and his dealings with others, he was always seeking not only to expand his own knowledge and understanding, but also to find new ways of communicating his remarkable insight to others. He is survived by his daughters, Else and Karin and grandchildren.

\section{Einar Tandberg-Hanssen ( Else Biesmann's Speech)}

Bonjour, God Dag, Hello,

It is our privilege to be invited to join you here in one of our fathers favorite cities and to share in this event with you. We are honored and pleased to be included.

Our father, as most of you may already know, was a very special gentleman. He taught us to enjoy nature and God's wondrous surroundings as well as the incredible creations of mere man. He seemed to know everything about everything but never came across as a know-it-all. His gentle and wise demeanor seemed to give everyone who met him the feeling that you were the most important person in the world to him at that moment.

He was a Francophile to the highest degree and would have chosen France as his home if circumstances would have permitted. Indeed, he spent the last few years of his life making sure that Karin and I had an opportunity to experience as much of France as possible in the way he had learned to love it - to see her many wonders and beautiful sights from north to south and east to west. Our annual expeditions taught us what a 
diverse and wonderful country France truly is. One of his favorite areas was Provence where we would end each of our French Adventures. Most likely his love for Provence had to do with his early years spent there with our mother when he was earning his Doctorate degree. He made life-long friends wherever he went, even with the hosts of several of the places to which we returned, including one of his favorites in Saintes Maries de la Mer to which he returned year after year. We always explored new areas but he made sure that we returned to two or three of the same places as anchor spots - the places that he liked the best. It seemed that everywhere we went we would find people that knew him and would welcome him with warm smiles and open arms. This welcome would of course extend to us as well as soon as he introduced us, which gave us a warm and happy feeling.

I hope I will not be considered blasphemous when I say that being in my father's presence was always like sitting at the feet of God and soaking in his radiance. I always held my father is such high regard. He was always on a pedestal for me and could do no wrong. Perhaps it is similar for most little girls, but I never outgrew this feeling for my father. He was always so wise and loving and forgiving because I could not possibly live up to what I thought were his standards. As it turned out, he did have high expectations of us but he accepted us as we were. But my impression of what he expected sure gave me a good goal to work for, although I am still fairly certain I have not yet attained it. I remember a time as a little girl, perhaps eight or nine years old, when I ran away from home after misbehaving and arguing with our mother and not being willing to admit my guilt. I ran and walked about a block from our home and found a big rock in an empty field where I decided I would stay. I remember sitting on my rock and pouting and wondering if anyone would care enough to find me. After a while, which seemed like a very long time, my father came walking by as I was sitting there on my rock, my new home. He found me sitting there and came and asked if he could sit on my rock. And then he sat with me in silence for a while. Eventually he began to talk to me about my new surroundings and where I had chosen to run away to - he loved rocks and knew exactly what kind of rocks and minerals we were sitting on and, although I don't remember his exact words, as he was explaining the feldspar and mica and granite in the rock, I knew he had forgiven me and it wasn't long before he persuaded me to come home with him. He assured me that we could come back and look at my rock again another time.

Our father often spoke of the times when we were growing up in Boulder, Colorado, as some of his best years. He was a devout, disciplined and caring father and spent a great deal of time making sure we were learning and gaining the best experiences. We were both given instruments to play and lessons in music and dancing and we were each required to practice each instrument for half an hour every morning before school. He would reward us by reading to us in the evenings after our family suppers. Karin and I would snuggle up on either side of him on the sofa so we could see any pictures in the books and eventually as we grew older we could follow along with the words. But our father did not read traditional childrens books to us - he would read things like the Time-Life series "The American Revolution", so our evening readings were not only a cozy family time, they were also educational, although sometimes gory and a little scary for little girls. As I looked back on this later, I am certain he was trying to teach us some history of the country we had chosen as our new home.

Our father was always very active in the church and one of my fondest and most secure memories of growing up was sitting next to my father in the church pew leaning on his shoulder with my hand slipped up into his crossed arms and holding his hand. Karin always sat on his other side between him and my mother - perhaps Karin was holding his other hand? Those times were the most serene and perfect days a child could possibly 
have to look back on. But there was the one morning driving home after church when to our surprise and alarm our father was pulled over to the side of the road by a policeman our perfect father had been driving faster than the speed limit and the policeman wanted to give him a ticket. I believe this is the only time I remember seeing my father feel shame or guilt, yet even this situation he handled in a calm and dignified, yet humbled, manner. He has always set a good example for us.

The importance of planning was something our father tried over and over to teach us. And it seems that planning trips was one of our father's favorite things to do. When Karin and I were just becoming teenagers we were fortunate to be included in another trip to explore Europe on our way to our beloved Norway because Pappa had an IAU conference to attend. We were indeed fortunate - every three years while we were growing up Pappa would bring us somewhere where the IAU meetings were being held and share the world's wonders with us. These trips were always planned to include visits to castles and the magnificent cathedrals created centuries before in the area where each conference was held as well as cathedrals all along our trip from the conference location to Norway. On this particular trip, when we were about 12 and 14 years old, we were taking several detours on our journey to see what we had begun to consider a few too many cathedrals. Being teenagers we had perhaps not yet come to appreciate the true magnificence of each these individual structures - each of them had unique features that he wanted to us to see and appreciate. The flying buttresses, a particularly fine stained glass window, an unusual baptismal font. The special features list was seemingly endless and in his view he would have loved to see every last one of them. We had not yet learned to understand the splendor of each of these exceptional works of art and finally we rebelled and told him "Not another cathedral!" To his great surprise we had seen enough cathedrals. In his wisdom he did not let us see his full disappointment, but we did note his surprise at our intolerance. We spent many years afterwards joking about our rebellion and Pappa tried to pick only the finest cathedrals for our future trips together. It became a family tradition to joke about our father's love of cathedrals and fortunately he was able to find others who shared his great love of cathedrals. When he traveled without us he would take in as many of them as he could. Our father loved to tell the story of one of his solo trips when he met a gentleman surveying a cathedral who walked with a limp. They struck up a conversation about the particular features of the cathedral they were in and soon my father learned that this gentleman, Mr. Dodge from Michigan, had received his limp by walking through a cathedral while looking up and admiring the soaring ceilings and since he was not looking where he was going he tripped and hurt his leg. The two of them exchanged information and were soon good friends and would get together periodically over the decades to discuss their latest travels and which cathedrals they should recommend to each other. Our father had found another kindred spirit. But our father was not only determined to teach us about ancient cultures and the finest manmade things in the world. He also wanted us to enjoy what God has given us and teach us to care for nature and those around us. From the time we were born we were taken for hikes and skiing trips. To begin with we were in backpacks on his back and then we were fitted with hiking boots or skis depending on the season and were given the love of the great outdoors. I was put in my first ski race at the ripe old age of two when we were still living in Norway. And both Karin and I were taken to a local downhill ski area when we were five and seven years old respectively after our move to Colorado. On our hikes Pappa taught us about the way fallen trees would normally twist their trunks to the right when they died but once in a while we would find a fallen tree that twisted to the left it was a marvel that became something we would learn to hunt for. He taught us about the mosses growing in the moist, shady areas along the 
normally dry, Colorado mountain trails, and about the lichens that grew in various colors on the rocks in the sun. There were the sounds of the creatures in the forest, around the mountain lakes and in the high rocky passes that we soon learned to identify. We would bring little books on our hikes teaching us about the beautiful birds and flowers all along our paths throughout the beautiful and rugged Colorado Rocky Mountains. On our American vacations we explored the great southwestern part of the US touring many American Indian ruins before it became fashionable to do so. Our parents had found a great appreciation for the handicrafts of the southwestern Indians. They had found another fascinating ancient culture that they wished to share with us and it was located in another beautiful, unusual landscape that our father found intriguing. It was another mixture of manmade and God-made beauty that he wished to share with us. During our vacations to our beloved Norway we were taught about the ancient Viking culture while exploring the woods, gently rolling mountains and farmlands of our native land. It is in our native land where we find the most peaceful paradise our father could share with us and preserve for us: our family cabin which is perched along a gently sloping fjord in the southern part of Norway where a few of his colleagues have also had an opportunity to visit. Our father gave us this treasure to love and cherish so we may maintain our family ties and continue our family gatherings. For our father's 80th birthday, our entire family gathered at the cabin. Once again our father did some excellent planning as there were so many of us arriving from America that we had to borrow rooms in the neighboring cabins, which our neighbors were happy to help Pappa with. The planning for the event was meticulous and everything went smoothly. A few years earlier we had all gathered for our mother's burial and Pappa had also planned things meticulously. Mamma and Pappa's friends and our Norwegian relatives joined us for a big luncheon following the interment in an elegant, old restaurant in town near the cabin. The day afterwards all the Americans went to Oslo for some sightseeing. Pappa had spent time in Oslo a few weeks beforehand preparing where we were to stay and how our large contingent of all ages would travel from place to sight-seeing place and enjoy the sights of Oslo. His planning included actually tracing the steps we would take and which trams we could all take from the hotel including the tram time-tables. He had always been an excellent tour guide and we were all looking forward to our sight-seeing adventure. After arriving in Oslo and checking into our hotel, we all gathered in the hotel lobby and proceeded to follow him like a long line of ducklings to the nearest tram stop. As we approached the spot where the tram was to stop to take us to town, we noticed our father's face acquire a priceless look - a combination of shock and dismay - as the tracks had been dug up and the train would no longer be coming to pick us up! But, as always, our ever resourceful father came up with Plan B and, after a little hiccup in his plans, we proceeded to tour Oslo with the best, most knowledgeable tour guide imaginable.

Thanks to our fathers enthusiasm for exploring the world, which was truly contagious, we were both smitten with a love of nature and bitten very early in life by a severe case of the travel bug. I now live in the woods watching the wildlife from our home and my jobs have been helping me to explore the world. Karin has lived for many years by the ocean and she creates beautiful things from shells and things that are found by the sea. We are both truly pleased to be included in this symposium honoring our father and feel very honored to be able to share a little bit about him from his daughters perspectives. Thank you again for inviting us.

Else Biesmann and Karin Brock the daughters of Einar, Jacquelyn and Jennifer the grand-daughters of Einar in Paris (Figure 2). 